\title{
Jarricot Dermatome Pain Test Validation as a Diagnostic Test of Organic Stress ${ }^{*}$
}

\author{
Rodríguez-Nogueira Óscar \\ Fundació Universitària del Bages (FUB); \\ Institut de Neuropsiquiatria i Adiccions \\ (INAD), Barcelona, Spain \\ Morera-Balaguer Jaume \\ Cardenal Herrera University (CEU), \\ Alicante, Spain
}

\author{
González-Caminal Griselda \\ Fundació Universitària del Bages (FUB), \\ Barcelona, Spain
}
Rodríguez-Ferreira Jose
Semente Psychology Center,
Lugo, Spain

\begin{abstract}
Objective: To validate the Jarricot dermatome pain test as a diagnostic test for an organic state of stress. Methods: Validity and reliability study of a test re-test for Jarricot dermatome pain test. Sample of 32 participants by volunteers. Two physiotherapists performed the reflex test measurement of Jarricot dermalgias. A psychologist administered the Hamilton anxiety test. Cohen kappa was used to calculate concordance and intraclass correlation coefficient to calculate reliability. Spearman coefficient was used to correlate the number of positive dermalgias with Hamilton anxiety. Results: The interobsevadores agreement was: pancreas 0.87 , jejunum 0.87 , descendant colon 0.93 , bile duct 0.90 , ascendant colon 0.84 , heart 0.75 , liver 0.75 , stomach 0.75 , gallbladder 0.78 , duodenum 0.74 , and ileum 0.51 . The intraobserver agreement was: heart 0.87 , liver 0.81 , pancreas 1 , jejunum 0.87 , descendant colon 0.86 , gallbladder 0.92 , ascendant colon 0.92 , stomach 0.75 , ileum 0.76 , bile duct 0.74 , and duodenum 0.61 . Interobserver ICC (the intraclass coefficient correlation) was 0.98 and ICC intraobservador was 0.99. The Spearman coefficient was 0.7. Conclusion: The test of Jarricot dermalgias reflex is valid and reliable, having a strong and significant correlation between the number of positive dermalgias test score and Hamilton anxiety. Although the correlation is strong and significant, it would be advisable to perform studies using probabilistic sample to confirm this evidence.
\end{abstract}

Keywords: dermalgia, somatization, stress, Hamilton test, physiotherapy

\section{Introduction}

According to the Spanish Ministry of Health, mental disorders were the most frequent cause of disease burden in Europe in 2008. Thus, depression is currently the fourth leading cause of morbidity and it is expected

\footnotetext{
*Acknowledgments: Institut de Neuropsiquiatria i Adiccions (INAD).

Rodríguez-Nogueira Óscar, Ph.D. candidate, Physiotherapy Department, Fundació Universitària del Bages (FUB); Institut de Neuropsiquiatria i Adiccions (INAD).

González-Caminal Griselda, Ph.D. candidate, Physiotherapy Department, Fundació Universitària del Bages (FUB).

Morera-Balaguer Jaume, Ph.D., Physiotherapy Department, Cardenal Herrera University (CEU).

Rodríguez-Ferreira Jose, psychologist, Semente Psychology Center.
} 
to become the second in 2020. WHO (the World Health Organization) estimates that up to $20 \%$ of the population will suffer from any psychological disorder in 2020. Likewise, those illnesses derived from any psychosocial risk occupy the fifth place within the causes with more incidence in the workplace and they rank in the first place regarded to the average of duration of the process and have a direct cost of between $6 \%$ and $14 \%$ above the average of other medical diseases; to that one should add the indirect costs derived from long periods of sick leave (Barsky, Orav, \& Bates, 2005). In the year 2000, ILO (the International Labour Organization) estimated that both the direct and indirect costs within the European Union related to mental health were $4 \%$ of the GDP (Liimatainen \& Gabriel, 2000).

The link between the alterations of the musculo-skeletal system and mental disorders is a revised constant in the last decades and there is evidence of their interrelationship (Araña, 2008; Kieffer, 2013; Benavides, Delclos, Benach, \& Serra, 2006). Corruble and Guelfi (2000) found out that $75 \%$ of the participants of his study diagnosed with depression showed muscular pains. Katja, Jakobi, Hoyer, Low, Höfler, and Wittchen (2010) concluded that there was a strong relationship between pain, anxiety and depression in a study carried out in Germany with a sample of 4,181 patients in the primary health. In Spain, the first study to determine the prevalence of the somatization syndrome was conducted by the team of Lobo, Garcia, Campos, Marcos, and Pérez (1996) and it was calculated to be $9.4 \%$, being back pain the most common symptomatology. Physical distress is thought to be one of the reasons that causes corporal symptomatology in patients with mental disorders (Jarcho \& Mayer, 2007; Posserud, Agerforz, Ekman, Bjornsson, Abrahamsson, \& Simren, 2004; Raison \& Miller, 2003; Kubzansky \& Koenen, 2007; McEwen, 1998; Bhatia \& Tandon, 2005). This distress controlls the visceral activity and causes an increase of the sympathetic tone in the gastrointestinal system and the heart through the autonomous nervous system (Bhatia \& Tandon, 2005; Roy-Byrne, Davidson, \& Kessler, 2008).

The current study takes the theoretical basis of reflex dermalgias according to Jarricot. These are defined as the cutaneous somatization in the nervous system of the corresponding visceras. Their studies are supported by the concept of dermatomes based on previous studies of Head and Dejerine (Lee, McPhee, \& Stringer, 2008; Gallardo, 2008). Experimental and clinical findings seem to prove that visceral and cutaneous vasomotor responses are parallel (Rome, 2009; Thieme \& Turk, 2006; Korr, 2000). Thus, under conditions of emotional stress, the nervous information will subdue both vasomotor tissues and cutaneous sudomotor innervated by that segment to a bombing of major efferents (Korr, 2008), reflecting the hypertonia in the dermis. The result will be a teno-cellulose myalgic reflex in the skin which will be easily evident in the emergency zones of the sensory nerve in the corresponding dermatome.

A reflex dermalgia is assessed by the technique of the skin rolling, which is aimed to assess the mobility between subcutaneous planes. This is done by the dynamic displacement of a skin-fold between the thumb and the forefinger. This will give evidence to the two elements by which the dermalgia is composed:

(1) A sign: progressive infiltration of the subcutaneous elements: reflex cellulitis;

(2) A symptom: pain caused by palpation which was painless before.

This reflex dermalgia lies in a given dermatome within a constant area, and it coincides with the vascular-nervous bundle piercing emergency point (Ricard, 2009; Jarricot, 1973). This study has only taken into account those dermalgias related to metameric projections of both the digestive organs and the heart (see Figure 1), taking into account the available evidence which links the diseases of these organs with states of 
stress (Jarcho \& Mayer, 2007; Posserud, Agerforz, Ekman, Bjornsson, Abrahamsson, \& Simren, 2004; Raison \& Miller, 2003; Kubzansky \& Koenen, 2007; McEwen, 1998; Bhatia \& Tandon, 2005).

There is always an exact overlap between the peak of pain and the area of maximum reflex cellulite. The pain caused by the skin rolling technique, which is delicate and painless in normal tissues, surprises by its intensity in the tissues of cellulite. This is, according to Jarricot, due to its sympatalgyc nature (Korr, 2000; Richard, 2009; Jarricot, 1973).

In a society where both psychological and psychosocial stress are a constant, the progress towards an early diagnosis of physical distress is something fundamental which will help both improving the symptoms and preventing further problems arising.

More and more patients attend on physiotherapy rooms suffering from somatic symptoms derivate from distress, being $75 \%$ of these consultations related to exclusively somatic symptoms (García, Campos, \& Marcos 1996). Despite the number of patients which attend these consultations, there is no awareness of any diagnostic test in physiotherapy which allows to differentiate if the etiology is the result of poor adaptation to the source of stress or if it is a musculoskeletal problem. Thus, the validation of this test allows us to establish an appropriate and quick diagnosis to prevent the symptomatology to establish and contribute to become chronic and this way closing a vicious circle from which it will be hard to get out (Agüera, Failde, Cervilla, Díaz-Fernández, \& Mico, 2010).

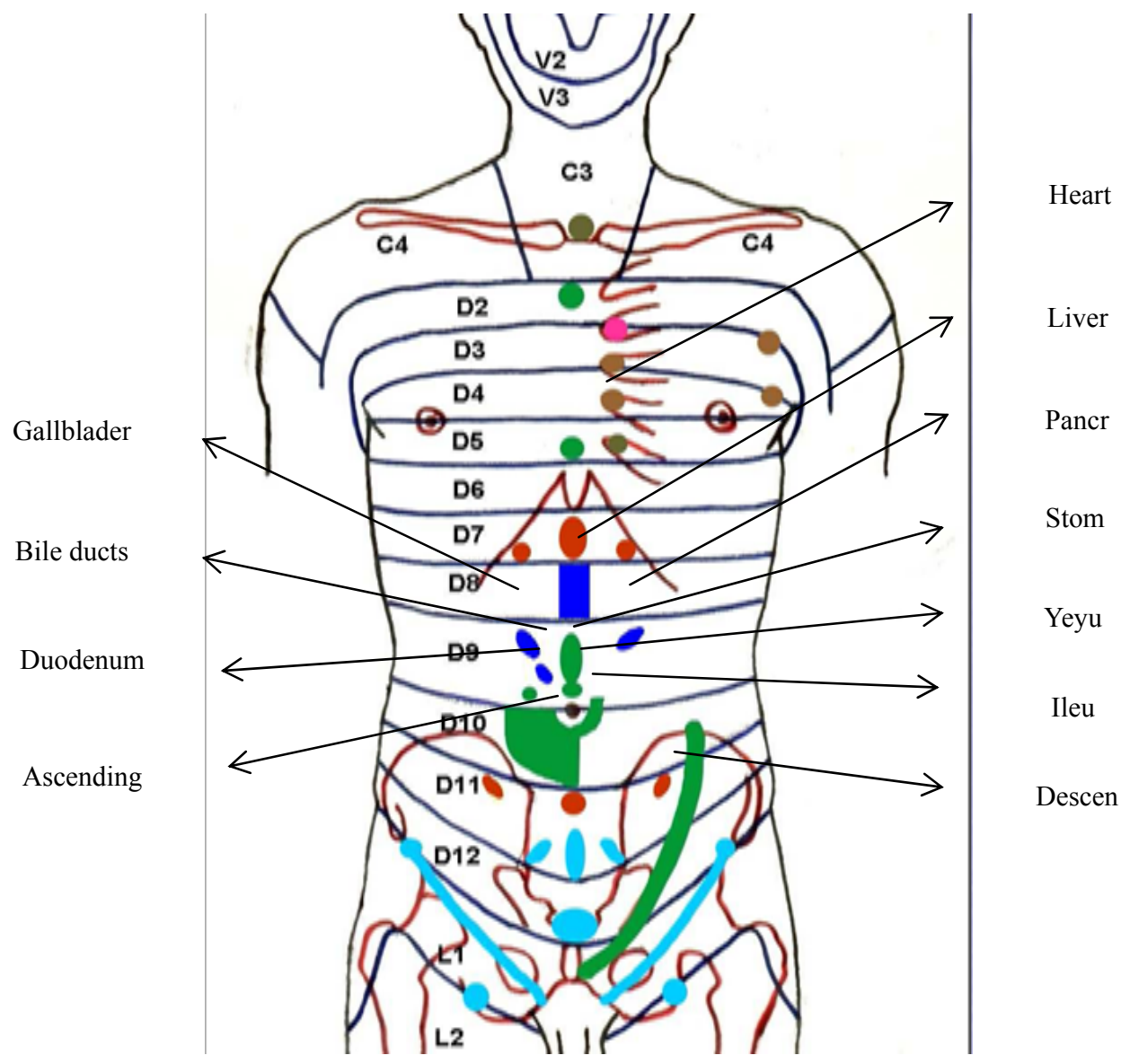

Figure 1. Reflex dermalgias according to Dr. Henri Jarricot. 


\section{Objective}

The objective is: To validate the reflex dermalgias test of Jarricot (TDRJ) taken as a test associated to the somatization in the dermis of the organic stress.

\section{Materials and Methods}

The materials and methods are: Study of the validity and reliability of the TDRJ through the test re-test system. Correlation between the numbers of positive dermalgias with the results of the anxiety test by Hamilton.

\section{Sample}

Field of study is: health professionals and administrative personal from the psychiatry and geriatric units of the Centre Forum Hospital del Mar. Study sample is a nonrandom sample of 32 workers whose participation was voluntary. Inclusion criteria is being older than 18, not having any toxic habit and not having taken any kind of psychotropic drugs in the last month. Exclusion criteria is the diagnosis of organic disease in the gastrointestinal system (stomach ulcer, gallstones, liver diseases, duodenal ulcer, irritable colon) or presence of Panic Attacks in the last three days. A significance level of 5\% was set and $90 \%$ of power in order to establish a correlation between the number of dermalgias and the Hamilton test. It was established that the significance of the correlation would be considered as unilateral and that 0.5 would be the minimum correlation which would be accepted.

Ethical principles were respected during the investigation: the Declaration of Helsinki, WHO recommendations, approval of the study by the Ethics Committee Clinical Research of the International University of Catalonia, and signature of the appropriate informed consent.

\section{Tools}

\section{Test of Reflex Dermalgias by Jarricot}

This test consists of 11 items that assess somatization in the dermis of a state of hyper tonicity of the sympathetic autonomous system. This should be assessed with the patient in the supine position and using the technique of. The dermalgia will be positive when finding pain and infiltration of subcutaneous tissues.

The following dermatomes were tested: D5 (heart), D8 (liver), D9 (right gallbladder, biliary tract below the stomach and pancreas center left), D10 (colon ascending to the right and duodenum, jejunum and ileum left and center), and D11 and D12 (descending colon to the left).

\section{Hamilton Anxiety Test}

We used the Spanish version of the Hamilton test which was made and validated by Carrobles, Costa, Del Ser, and Bartolomé (1986). It is a hetero applied scale of 14 items, 13 of them related to signs and anxiety symptoms and the last one which evaluates the patient behavior during his visit. Each item is marked from 0 to 4 points each, assessing both their intensity and frequency. There are two partial scores corresponding to psychic anxiety (items 1-6,14) and somatic anxiety (items 7-13). The final score corresponds to the sum of the two partial with a range from 0 to 56 points. This can be divided into two scores which correspond to anxiety. 


\section{Procedure}

The evaluation was carried out at the Forum Center Hospital del Mar during the participants' working time. Two researchers performed three measurements of the TDRJ with a 30-minute interval between the different measurements. The dossiers of data compilation were randomly numbered in order to maintain the anonymity of participants and blind the researchers. It contained four sheets of assessment, three for the TDRJ and one for the Hamilton test. The Hamilton test was applied between the first and the second measurement of the TDRJ.

To follow the same method, the order in which the dermalgias were measured was from ascending to descending starting with the left side of the patient: heart, liver, pancreas, stomach, jejunum, ileum, the descending colon, gallbladder, paths bile, duodenum, and ascending colon.

\section{Data Analysis}

Interobserver agreement was analyzed in each of the items of the TDRJ through Cohen's Kappa. Reliability was measured by ICC (the intraclass coefficient correlation). The Spearman correlation coefficient was used to evaluate the relationship between the number of dermalgias assessed by the investigator 1 and the Hamilton test score. The analysis of the obtained data was carried out by the statistic program SPSS 18.

\section{Results}

\section{Description of the Population Being Studied}

The subjects were 32 workers at the Forum Center Hospital del Mar, $68.75 \%(n=22)$ women and $31.25 \%$ $(n=10)$ men. The average age of the population was slightly higher in women (39.14) compared to men (36.20), while the standard deviation did not make many differences: (11.74) in women and (11.06) in men (see Table 1).

Table 1

Population Study Description

\begin{tabular}{llll}
\hline & Women & Men & Total \\
\hline Mean Age & $39.14(11.74)$ & $36.20(11.06)$ & $38.22(11.44)$ \\
Age range & $22-59$ & $22-54$ & $22-59$ \\
Clinical assistant & 11 & 3 & 14 \\
Nurses & 8 & 3 & 11 \\
Administrative & 0 & 2 & 2 \\
Doctor & 1 & 2 & 3 \\
Supervisor & 1 & 0 & 1 \\
Social worker & 1 & 0 & 1 \\
Total & 22 & 10 & 32 \\
\hline
\end{tabular}

\section{Results of Interobserver and Intraobserver Agreement}

The interobservers agreement was very good in five dermalgias (pancreas 0.87 , jejunum 0.87 , down colon 0.93 , biliary tract 0.90 , and ascending colon 0.84 ), it was also good in another five (heart, liver, and stomach 0.75 , gallbladder 0.78 , and duodenum 0.74 ) and it was moderate in one of them (ileum 0.51) (see Table 2).

The intraobserver agreement was very good in seven of them (heart 0.87 , liver 0.81 , pancreas 1 , jejunum 0.87 , descending colon 0.86 , gallbladder 0.92 , ascending colon 0.92 ), good in three (stomach 0.75 , ileum 0.76 , and bile 0.74 ) and it was moderated in one (duodenum 0.61) (see Table 2). 
Table 2

Cohen's Kappa Index for 11 Dermalgias Interobserver and Intraobserver

\begin{tabular}{|c|c|c|c|c|}
\hline \multirow{2}{*}{ Dermalgia } & \multicolumn{2}{|c|}{ Interobserver } & \multicolumn{2}{|c|}{ Intraobserver } \\
\hline & Kappa index & Degree agreement & Kappa index & Degree agreement \\
\hline D5 - Heart & 0.75 & Good & 0.87 & Very good \\
\hline D8 - Liver & 0.75 & Good & 0.81 & Very good \\
\hline D9 - Pancreas & 0.87 & Very good & 1.00 & Very good \\
\hline D9 - Stomach & 0.75 & Good & 0.75 & Good \\
\hline D9 - gallbladder & 0.78 & Good & 0.92 & Very good \\
\hline D9 - bile ducts & 0.90 & Very good & 0.74 & Good \\
\hline D10 - Jejunum & 0.87 & Very good & 0.87 & Very good \\
\hline D10 - Duodenum & 0.74 & Good & 0.61 & Moderate \\
\hline D10 - ascending Colon & 0.84 & Very good & 0.92 & Very good \\
\hline D10 - Ileum & 0.51 & Moderate & 0.76 & Good \\
\hline D11 and 12 - Descending colon & 0.93 & Very good & 0.86 & Very good \\
\hline
\end{tabular}

\section{Interobserver and Intraobserver Results ICC}

The reliability of the interobserver and intraobserver results was measured by using the intraclass correlation coefficient being the results 0.98 and 0.99 respectively (see Tables 3 and 4).

The value of the Spearman correlation coefficient between the number of positive reflex dermalgias and the Hamilton score test was 0.7 ( $p$-value $<0.05$ ).

Table 5 shows the average of positive reflex dermalgias and the Hamilton score test stratified by sex. We can observe how women score higher both in one test and the other.

Table 3

Interobserver ICC Results

\begin{tabular}{llll}
\hline & $X+S D$ & ICC & IC 95\% ICC \\
\hline Observer 1 & $6.31+3.30$ & 0.98 & {$[0.95,0.99]$} \\
Observer 2 & $6.66+3.36$ & & \\
\hline
\end{tabular}

Table 4

Intraobserver ICC Results

\begin{tabular}{llll}
\hline & $X+S D$ & ICC & IC 95\% ICC \\
\hline Observer 1 & $6.31+3.30$ & 0.99 & {$[0.98,0.99]$} \\
Observer 1 bis & $6.56+3.13$ & & \\
\hline
\end{tabular}

Table 5

Dermalgias Average Test Score and Hamilton Test Score Separated by Gender

\begin{tabular}{llc}
\hline Gender & Average dermalgias & Average Hamilton \\
\hline Women & 8 & 15.73 \\
Men & 2.6 & 5.30 \\
Total & 6.31 & 12.47 \\
\hline
\end{tabular}

\section{Discussion and Conclusion}

In the present study, we have been able to confirm that the TDRJ is a valid and reliable test which maintains a strong and positive correlation with the anxiety text of Hamilton. 
Out of the 11 items which make up the test, only the ileum dermalgia interobserver and Intra duodenum were found to have moderate kappa index. We believe that it would be worthy to point out that the extension of these dermalgias is small and also that they are located in a very sensitive area near the navel. Being this added to the pain provoked by the positive dermalgia could make you incur in false positives when the time between rating (30 minutes) is scarce, not leaving the necessary tissue rest needed between them. Under normal conditions each dermalgia is tested only once, so that there is no hypersensitivity reached by a previous review, and this increases more the reliability of the test. One important point to highlight is that in the other nine items the degree of agreement was very satisfactory.

The time lapse between assessments was established in 30 minutes by agreement and that is the time provided for the administration of the test of Hamilton. Thus participants could finish the first review, take the test and continue to do the second assessment without having to wait. Due to the fact that participants were working, it was convenient to expedite all the procedures so they could return to their jobs as soon as possible.

The Spearman coefficient to obtain the correlation between the TDRJ and the test of Hamilton was 0.7. It was observed that the greater the number of positive dermalgias, the higher the results in the test of Hamilton. This correlation was one of the goals of this study, which depended on the first validation of the TDRJ.

Stress is a state of adaptation to situations that we interpret as threatening. If this stress is frequent or permanently kept, it can produce physical discomfort or diseases. The current crisis seems to be a huge breeding ground for the growth of this type of pathologies. The present study was decided to be performed at the Forum Center Hospital del Mar and at the time of the data collection, the hospital's management was negotiating the implementation of a redundancy of 194 workers with the works councils. The staff was living a climate of special tension as reflected in most of the participants, so we thought it was the suitable population for this study.

Table 5 shows the average dermalgias and the score of the Hamilton test by sex. Knowing that scoring < 17 in the Hamilton test, we obtain a mild anxiety (Hamilton, 1959) and our study population is a sub-clinical population in which no one had a diagnosis of anxiety or taking psychotropic drugs, a score average of 15.73 in women can be categorized as a state of high stress, just what is TDRJ measure, in women whose average is 8 , so it could indicate the presence of stress. In men, an average of 5.30 in the test of Hamilton is not significant, nor is the average of 2.6 dermalgias, indicating absence of stress. These facts are consistent with the literature that women suffer a higher prevalence in generalized anxiety disorders and pains of psychosomatic origin (Domes, Schulze, \& Bottger, 2010; Ros, Comas, \& García, 2010).

The use of some updated references has to do with the lack of physiotherapy research, as this is a young science that is beginning to build its evidence. This leads us to base our research on principles and relationships of anatomy and physiology discovered and studied in the 70s, which we think it is necessary to start our route towards the scientific evidence itself.

The present study is favorable when saying that the TDRJ is valid and reliable for assessing stress, there is being a strong correlation between the TDRJ and the Hamilton test of anxiety. Through this viscero-cutaneous reflex, we obtain information about the state of stress of a person being able to clarify the origin of his/her symptomatology. The application of this test involves the use of an easy-to-use tool and low costs in the physiotherapy rooms, avoiding periods of expensive and ineffective rehabilitation that can lead to the chronicity of the symptomatology. We have not found in the literature studies with objectives similar to ours, so we recommend its implementation in order to have more evidence in this field. 
The results of this study can be applied to the daily clinical practice, in Professional Physiotherapy, psychology or medicine. It opens a door to interdisciplinary team, which is highly necessary between theose three branches in the health service. We live in a time when there is more and more relation between the psychological variables and physical problems, and it is essential that physiotherapists have instruments for measurement rapid, inexpensive, valid and reliable measurement, allowing us to determine the psychological characteristics of the patient that will serve us to guide our treatment or to refer the relevant professional.

\section{References}

Agüera, L., Failde, I., Cervilla, J. A., Díaz-Fernández, P., \& Mico, J. A. (2010). Medically unexplained pain complaints are associated with underlying unrecognized moodisorders in primary care. Family Practice, 11, 11-17.

Araña, S. (2008). Diagnósticos y prescripciones en salud mental, atención primaria y Incapacidad laboral temporal. Ministerio de Trabajo. Madrid.

Barsky, A. J., Orav, E. J., \& Bates, D. W. (2005). Somatization increases medical utilization and costs independent of psychiatric and medical comorbidity. Arch. General Psychiatry, 62, 903-10.

Benavides, F. G., Delclos, J., Benach, J., \& Serra, C. (2006). Lesiones por accidentes de trabajo, una prioridad en salud pública. Revista Española de Salud Publica, 80, 553-65.

Bhatia, V., \& Tandon, R. K. (2005). Stress and the gastrointestinal tract. Journal of Gastroenterology \& Hepatology, $20,332-9$.

Carrobles, J. A., Costa, M., Del Ser, T., \& Bartolomé, P. (1986). La práctica de la terapia de conducta. Valencia: Promolibro.

Corruble, E., \& Guelfi, J. (2000). Pain compleints in depressed inpatients. Psychopatology, 33, 307-9.

Domes, G., Schulze, L., Bottger, M., Grossmann, A., Hauenstein, K., Wirtz, P., Heinrichs, M., \& Herpertz, S. (2010). The neural correlates of sex differences in emotional reactivity and emotion regulation. Human Brain Mapping, 31, 758-69.

Gallardo, D. R. J. (2008). La inervación sensitiva segmentaria, dermatomas, miotomas y esclerotomas. Revista Chilena de Anestesia, 37, 26-38.

García, J., Campos, R., \& Marcos, G. (1996). Somatisation in primary care in Spain: II. Differences between somatisers and psychologisers. Working group for the study of the psychiatric and psychosomatic morbidity in Zaragoza. The British Journal of Psychiatry, 168, 348-53.

Hamilton, M. (1959). The assessment of anxiety states by rating. British Journal of Medical Psychology, 32, 50-55.

Jarcho, J. M., \& Mayer, E. A. ( 2007). Stress and irritable bowel syndrome. Primary Psychiatry, 14, 74-78.

Jarricot, H. (1973). Des certaines relations viscéro-cutanees métamériques en acupuncture. Méridien, 21-22.

Katja, B., Jakobi, F., Hoyer, J., Low, N., Höfler, M., \& Wittchen, H. U. (2010). Social Psychiatry \& Psychiatric Epidemiology, 45 , 89-104.

Kieffer, C. (2013). Quelle reconnaissance des pathologies psychiques liées au travail? Une étude sur 10 pays européens. Eurogip. Paris.

Korr, I. (2008). Bases fisiológicas de la osteopatía. Madrid: Editorial Médica Panamericana.

Korr, I. (2000). The emerging concept of the osteopathic lesion. Journal of the American Osteopathic Association, 100(449), 60.

Kubzansky, L. D., \& Koenen, K. C. (2007). Is post-traumatic stress disorder related to development of heart disease? Future Cardiology, 3, 153-156.

Lee, M., McPhee, R., \& Stringer, M. (2008). An evidence-based approach to human dermatomes. Clinical Anatomy, 21(5), 363-373.

Liimatainen, M. R., \& Gabriel, P. (2000). Mental health in the workplace. Geneva: International Labour Office.

Lobo, A., Garcia, J., Campos, R., Marcos, G., \& Pérez, M. J.(1996). Somatisation in primary care in Spain: I. Estimates of prevalence and clinical characteristics; Working group for the study of the psychiatric and psychosomatic morbidity in Zaragoza. British Journal of Psychiatry, 168(3), 344-348.

McEwen, B. S. (1998). Protective and damaging effects of stress mediators. The New England Journal Medicine, 338, 171-179.

Posserud, I., Agerforz, P., Ekman, R., Bjornsson, E. S., Abrahamsson, H., \& Simren, M. (2004). Altered visceral perceptual and neuroendocrine response in patients with irritable bowel syndrome during mental stress. International Journal in Gastroenterology, 53,1102-1108.

Raison, C. L., \& Miller, A. H. (2003). When not enough is too much: The role of insufficient glucocorticoid signaling in the pathophysiology of stressrelated disorders. American Journal of Psychiatry, 160, 1554-1565. 
Ricard, F. (2009). Tratado de osteopatía visceral y medicina interna: Tomo III sistema genitourinario. Madrid: Editorial Médica Panamericana.

Rome, P. L. (2009). Neurovertebral influence upon the autonomic nervous system: Some of the somato-autonomic evidente to date. Chiropractics, 39, 2-17.

Ros, S., Comas, A., \& García, M. (2010). Validación de la Versión Española del Cuestionario PHQ-15 para la evaluación de síntomas físicos en pacientes con trastornos de depresión y/o ansiedad. Actas Españolas de Psiquiatría, 38, 345-357.

Roy-Byrne, P. P., Davidson, K. W., \& Kessler, R. C. (2008). Anxiety disorders and comorbid medical illness. General Hospital Psychiatry, 30, 208-225.

Thieme, K., \& Turk, D. C. (2006). Heterogeneity of psychophysiological stress responses in fibromyalgia syndrome patients. Arthritis Research \& Therapy, 8, R9. 